\title{
Quantitative relationship between atmospheric phenol vapour and phenol in the urine of workers in Bakelite factories
}

\author{
HATSUE OHTSUJI and MASAYUKI IKEDA \\ Department of Public Health, Kyoto University Faculty of Medicine, Kyoto, Japan
}

\begin{abstract}
Ohtsuji, H., and Ikeda, M. (1972). Brit. J. industr. Med., 29, 70-73. Quantitative relationship between atmospheric phenol vapour and phenol in the urine of workers in Bakelite factories. A survey in Bakelite factories revealed that the urinary level of total phenol, free plus conjugated, increased in proportion to the phenol concentration to which the subject was exposed in his working environment. This indicates that analysis of urine for phenol is valuable for the monitoring of exposure to phenol in air.

The results also suggest that the human lung takes up phenol very efficiently. The increase in urinary phenol was entirely attributable to conjugated phenol; regardless of exposure, no significant change was observed in free phenol concentration. Ethereal sulphate or ethereal glucuronide had poor validity as an index of exposure.
\end{abstract}

Since the beginning of this century the use of synthetic resins has been spreading in every field of life. Bakelite, or phenol resin, is among the most popular resins, even though somewhat old-fashioned.

Following previous reports on the metabolism of styrene (Ohtsuji and Ikeda, 1971) and the use of analyses of urinary metabolites for monitoring the exposure of workers in styrene resin factories (Ohtsuji and Ikeda, 1970), we report, in the present paper, that the urinary concentration of phenol (i.e., total phenol or, preferably, conjugated phenol) is a good index of exposure to atmospheric phenol vapour in Bakelite factories.

\section{Urine samples}

\section{Materials and methods}

The survey was conducted in the autumn. Urine samples were collected from male workers who had been engaged in laying together paper sheets impregnated with phenol resin to produce Bakelite boards. The workers were exposed to phenol from 8.00 a.m. to noon and from 1.00 p.m. to 4.00 p.m. daily. This type of workshop was chosen for study as the labour was performed in closed rooms where environmental concentrations of phenol were fairly stable. Samples from office workers were also collected for examination of levels of metabolites in controls.

Analysis of urine Phenols (total, free, and conjugated) were determined colorimetrically by the method previously described (Ikeda, 1964) using Gibbs' colour reagent. The specificity of the method and the origin of phenol in urine have been discussed by van Haaften and Sie (1965). The method does not record $p$-cresol.

Ethereal glucuronide was measured as previously described (Ikeda, 1964) with naphthoresorcinol as a colour-developing reagent.

Determination of ethereal sulphate was based on the method of Bertolacini and Barney (1957) as modified by Ohmori and Hara (1966). Inorganic sulphate was determined on $0.15 \mathrm{ml}$ of urine, which was mixed in a tube with $0.45 \mathrm{ml}$ of water, $0.6 \mathrm{ml}$ of $1 \mathrm{M}$ acetate buffer $(\mathrm{pH} 4.0$ ), and $0.3 \mathrm{ml}$ of $1 \mathrm{mg} / \mathrm{ml}$ potassium oxalate to remove interfering calcium ion. After the addition of $5.4 \mathrm{ml}$ of $31.7 \%$ ethanol/water (v/v) and about $20 \mathrm{mg}$ of barium chloranilate, the tube was shaken vigorously for 15 minutes and centrifuged. The red colour was measured at $530 \mathrm{~nm}$. For the determination of total sulphate, urine was sealed in an ampoule with 3 volumes of $1 / 3 \mathrm{~N} \mathrm{HCl}$, and heated at $100^{\circ} \mathrm{C}$ for $1 \mathrm{hr}$. A portion, $0.6 \mathrm{ml}$, of the hydrolysate was added to $1 \mathrm{M}$ acetate buffer (pH 4.0) and enough $0.25 \mathrm{~N} \mathrm{NaOH}$ to bring the $\mathrm{pH}$ to $4 \cdot 0$. Sulphate was then 
analysed as described above. The two procedures were carried out on the same urine sample and the difference between the two results gave the ethereal sulphate.

Creatinine concentration was determined by the method described previously (Ikeda and Ohtsuji, 1969a).

Results were in some instances adjusted to a specific gravity of urine of 1.016 as described by Elkins and Pagnotto (1965) or expressed in terms of creatinine concentration (Jackson, 1966).

\section{Phenol in air}

Two midget impinger tubes, each containing $15 \mathrm{ml}$ of

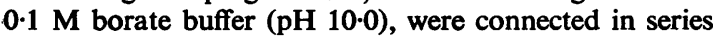
with a pump-battery-flow meter assembly ("portable pump', Mines Safety Appliances Co., Pittsburg, U.S.A.) and 5 to $10 \mathrm{l}$. of air were passed through them at about 21 ./min. A $3.5 \mathrm{ml}$ portion of the buffer (diluted when necessary with fresh buffer) was taken from each tube, $0.1 \mathrm{ml}$ of $0.2 \%$ 2,6-dichloroquinone chloroimide in ethanol (Gibbs' reagent) was added (Gibbs, 1927), and the resulting blue colour was measured at $610 \mathrm{~nm} 20$ minutes after the addition. At least five determinations were carried out at various sites in each room, the average of which was taken to represent the environment.
Statistical analyses

Urinary data were assumed to be log-normally distributed (Heath, 1967) for statistical analyses. Regression lines were calculated with weighting for the numbers of samples (Snedecor, 1956).

\section{Results and discussion}

As observed in toluene metabolism (Ikeda and Ohtsuji, 1969b), the total urinary phenol concentration varied proportionately to the environmental phenol concentration (Fig. 1A, C, E). The regression lines cut the vertical axis above zero. It is well known that human subjects, even with no known exposure to phenol or its mother compounds, excrete phenolic compounds into urine (Williams, 1959), which may be derived from aromatic amino acids or food components (see also van Haaften and Sie (1965)). The concentration of conjugated phenol (the main components of which are presumably phenyl glucuronide and phenyl sulphate, as observed by Parke and Williams (1953) in rabbits' urine) also

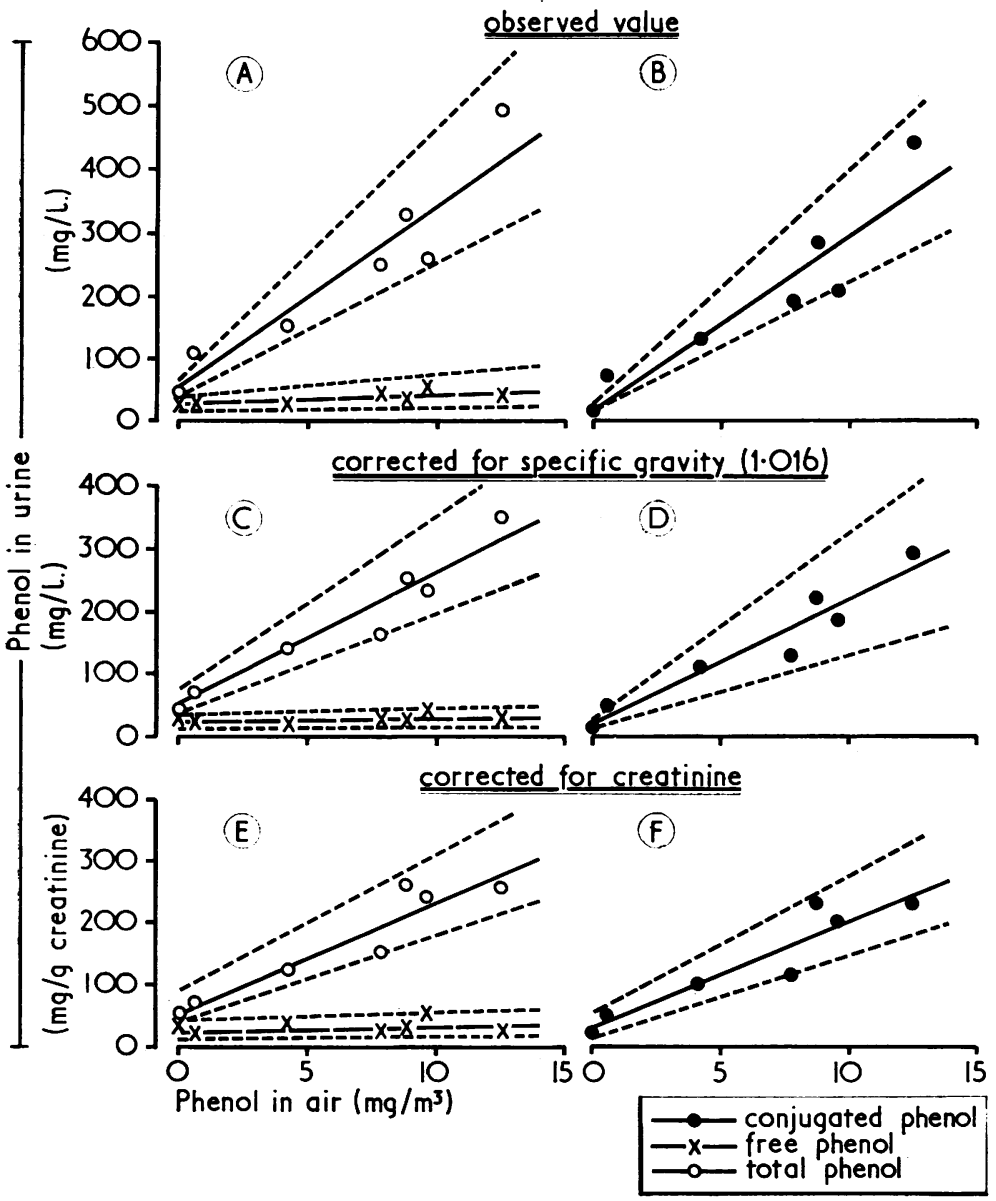

FIG. 1. Relation between environmental phenol concentration in air and urinary phenols: (A) total and free phenols (observed values); (B) conjugated phenol (observed values); (C) total and free phenols (corrected to a specific gravity of 1.016); (D) conjugated phenol (corrected to a specific gravity of $1 \cdot 016)$; (E) total and free phenols (corrected to constant creatinine concentration); (F) conjugated phenol (corrected to constant creatinine concentration).

Symbols show geometric means. Lines are weighted regression lines for the means (- ) together with those for the S.D. ranges $(---)$. The numbers of samples represented by each point were as follows: $0 \mathrm{mg} / \mathrm{m}^{3}, 7 ; 0.6 \mathrm{mg} / \mathrm{m}^{3}, 7 ; 4.2$ $\mathrm{mg} / \mathrm{m}^{3}, 4 ; 7.8 \mathrm{mg} / \mathrm{m}^{3}, 8 ; 8.8 \mathrm{mg} / \mathrm{m}^{3}$, $8 ; 9.6 \mathrm{mg} / \mathrm{m}^{3}, 8$; and $12.5 \mathrm{mg} / \mathrm{m}^{3}$, 7. Urine samples were collected at 3.00 p.m. towards the end of the day's exposure. 
increased linearly with environmental phenol concentration. The concentration of free (i.e., unconjugated) phenol, on the contrary, was essentially independent of environmental phenol. This suggests that human subjects possess ample capacity to conjugate absorbed phenol as glucuronide or sulphate under the conditions studied, and perhaps up to the phenol concentration of $19 \mathrm{mg} / \mathrm{m}^{3}$, the A.C.G.I.H. threshold limit value for 1969 .

From the results shown in Fig. 1C a tentative calculation was made to estimate the efficiency with which phenol is taken up through the lung. The regression line for total urinary phenol cuts the ordinate at $55 \mathrm{mg} / \mathrm{l}$. and reaches $262 \mathrm{mg} / \mathrm{l}$. when phenol in air is $10 \mathrm{mg} / \mathrm{m}^{3}$. The difference is attributable to phenol absorbed after inhalation. Because the half-life of phenol in man is short (Parke and Williams, 1953; also the data in Fig. 2), it may be reasonable to assume that the intake and excretion of phenol had come to a balance by the time urine was sampled at 3.00 p.m., as was the case in toluene metabolism (Ogata, Nagao, and Tomokuni, 1968). If we assume that the respiratory volume under working conditions was 15 to $201 . / \mathrm{min}$ and that the urine output was around $50 \mathrm{ml} / \mathrm{hr}$, the estimated amount of environmental phenol inhaled was about $10.5 \mathrm{mg} / \mathrm{hr}$, i.e., $10 \times(15$ to 20$) \times 60 / 1,000$, while the amount of urinary phenol attributable to phenol absorbed was $10.2 \mathrm{mg} / \mathrm{hr}$, i.e., $(262-55) \times$ $50 / 1,000$. This agreement between the two estimates, even though approximate, indicates that phenol was taken up very efficiently through the lungs.
Other examples are given in Fig. 2A and $\mathrm{B}$ to show that the urinary concentration of phenol reflects the exposure to environmental phenol. Urine samples collected at 8.00 a.m. (before exposure) on the sixth day of work after five consecutive working days contained only a little phenol. One working day with exposure caused a sharp increase in urinary phenol concentration, which returned to normal after the subjects were removed from the environment for two days (Fig. 2A) or even for one (Fig. 2B). Exposure to phenol on the next day again resulted in a rise of urinary phenol. These alterations were entirely attributable to the changes in concentration of conjugated phenol; consistent with the results given in Fig. 1, the levels of free phenol remained essentially unchanged regardless of exposure. The pre-exposure level on the sixth day of work in Fig. 2A was significantly $(P>0.05)$ higher than the level in the urine of controls when tested by $t$ test, but this may not mean accumulation of phenol in the body during the working day because the corresponding preexposure level in Fig. 2B was almost in the normal range.

Neither urinary ethereal sulphate nor urinary ethereal glucuronide was a good index of phenol exposure. As shown in Figs. 3 and 4, the regression lines for both compounds have very small gradients and wide S.D. ranges. This poor validity of ethereal sulphate as an exposure index agrees with the poor reliability of the urinary sulphate ratio as an index of benzene exposure. The phenol test is now taking the

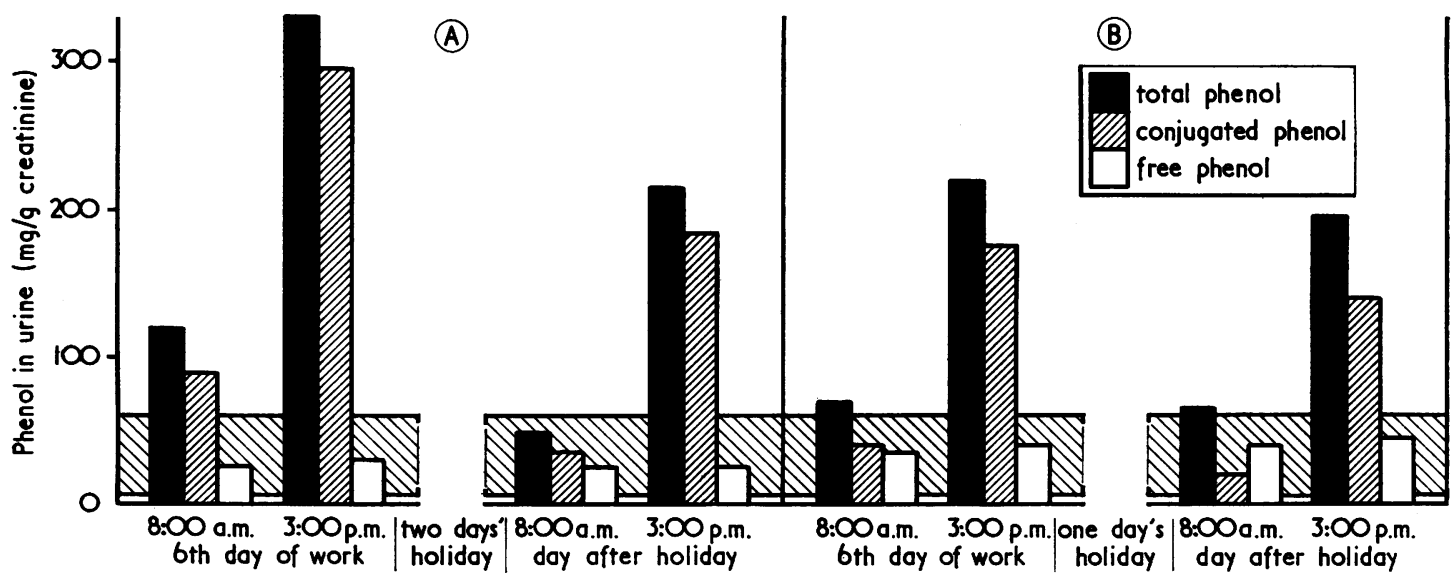

FIG. 2. Changes in urinary concentrations of phenols after exposure to environmental phenol. Columns show geometric means. The shaded zone on the vertical axis shows fiducial limit $(P=0.95)$ ranges of normal values for total phenol (Ikeda and Ohtsuji, 1969a).

(A) Four urine samples from men exposed to $8.8 \mathrm{mg} / \mathrm{m}^{3}$ phenol were collected at each time period, i.e., at 8.00 a.m. before exposure and at 3.00 p.m. Two days without exposure lay between the two days with exposure (shown with thick lines on the horizontal axis).

(B) Six urine samples from men at 7.8 or $9.6 \mathrm{mg} / \mathrm{m}^{3}$ phenol. One day without exposure lay between the two days with exposure. 

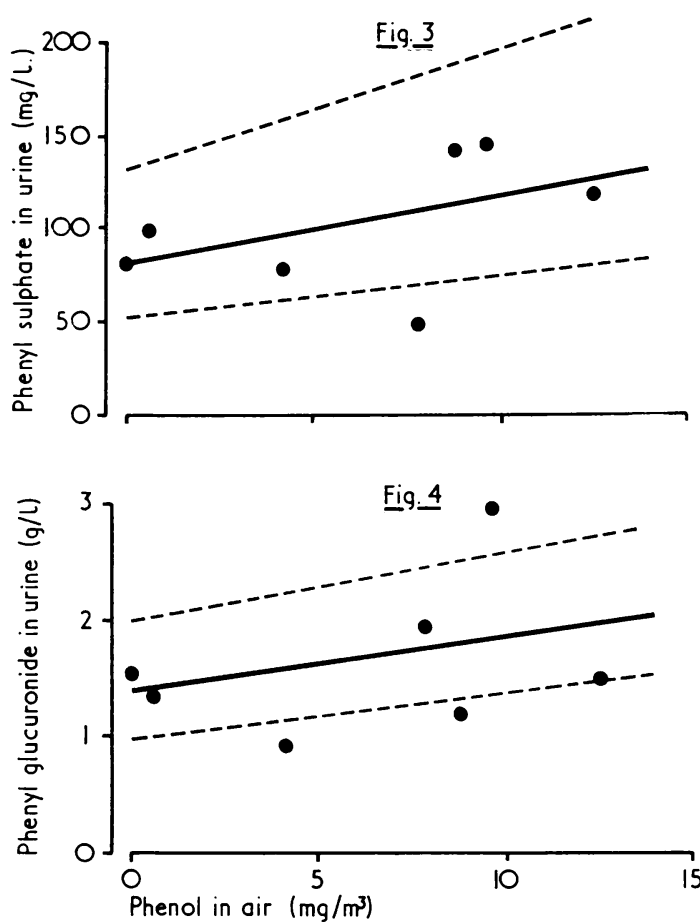

FIG. 3. Urinary excretion of ethereal sulphate from men exposed to phenol in air at various concentrations.

FIG. 4. Urinary excretion of ethereal glucuronide from men exposed to phenol in air at various concentrations.

The lines are weighted calculated regression lines ( - ) together with those for the S.D. ranges (-- ). The numbers of samples are as described in Fig. 1.

place of the sulphate ratio test as the environmental exposure to benzene lessens. (For a review, see Browning, 1965.) The highest concentration of phenol investigated here was $12.5 \mathrm{mg} / \mathrm{m}^{3}$, which is equivalent to $10.3 \mathrm{mg} / \mathrm{m}^{3}$ (3.3 p.p.m.) of benzene on an equimolar basis but less when the low efficiency with which benzene is absorbed (Nomiyama and Nomiyama, 1969) is borne in mind. According to Elkins (1954), benzene concentrations as high as 40 p.p.m. are necessary to change the sulphate ratio.

The authors are grateful to Professor M. Nishio, of the Department of Public Health, Kyoto University Faculty of Medicine, Kyoto, for his interest and support. Thanks are also due to Mrs. S. Miyahara, of Kyoto Labour Standard Bureau, Kyoto, for her help in obtaining urine samples. This work was supported in part by a grant from the Japanese Ministry of Education to one of us (H.O.) and a grant from Fujiwara Memorial Fund.

\section{References}

Bertolacini, R. J., and Barney, J. E. (1957). Colorimetric determination of sulfate with barium chloranilate. Analyt. Chem. (Wash.), 29, 281-283.

Browning, E. (1965). Toxicity and Metabolism of Industrial Solvents, pp. 8-11. Elsevier, Amsterdam and London.

Elkins, H. B. (1954). Analyses of biological materials as indices of exposure to organic solvents. Arch. industr. Hyg., 9, 212-222.

and Pagnotto, L. D. (1965). Is the 24-hour urine sample a fallacy? Amer. industr. Hyg. Ass. J., 26, 456-460.

Gibbs, H. D. (1927). Phenol tests. III. The indophenol test. J. biol. Chem., 72, 649-664.

van Haaften, A. B., and Sie, S. T. (1965). The measurement of phenol in urine by gas chromatography as a check on benzene exposure. Amer. industr. Hyg. Ass. J., 26, 52-58.

Heath, D. F. (1967). Normal or log-normal: appropriate distributions. Nature (Lond.), 213, 1159-1160.

Ikeda, M. (1964). Enzymatic studies on benzene intoxication. J. Biochem. (Tokyo), 55, 231-243.

- and Ohtsuji, H. (1969a). Hippuric acid, phenol, and trichloroacetic acid levels in the urine of Japanese subjects with no known exposure to organic solvents. Brit. $J$. industr. Med., 26, 162-164.

- and - (1969b). Significance of urinary hippuric acid determination as an index of toluene exposure. Brit. $J$. industr. Med., 26, 244-246.

Jackson, S. (1966). Creatinine in urine as an index of urinary excretion rate. Hlth Physics, 12, 843-850.

Nomiyama, K., and Nomiyama, H. (1969). Sex difference in benzene uptake in man. Industr. Hlth (Kawasaki), 7, 8687.

Ogata, M., Nagao, I., and Tomokuni, K. (1968). Urinary hippuric acid excretion in persons exposed to various concentrations of toluene in an exposure chamber. Jap. J. industr. Hlth, 10, 64-74 (in Japanese).

Ohmori, S., and Hara, I. (1966). A rapid colorimetric determination of sulphate in urine with barium chloranilate. Proceedings of the Osaka Prefectural Public Health Institute, Industrial Health Edition No. 3, pp. 32-55 (in Japanese).

Ohtsuji, H., and Ikeda, M. (1970). A rapid colorimetric method for the determination of phenylglyoxylic and mandelic acids. Brit. J. industr. Med., 27, 150-154.

—, and — (1971). The metabolism of styrene in the rat and stimulatory effect of phenobarbital. Toxicol. appl. Pharmacol., 18, 321-328.

Parke, D. V., and Williams, R. T. (1953). Studies in detoxication. 54. The metabolism of benzene. (a) The formation of phenylglucuronide and phenylsulphuric acid from $\left[{ }^{14} \mathrm{C}\right]$ benzene. (b) The metabolism of $\left[{ }^{14} \mathrm{C}\right]$ phenol. Biochem. J., 55, 337-340.

Snedecor, G. W. (1956). Statistical Methods, 5th ed. Iowa State University Press, Ames, Iowa.

Williams, R. T. (1959). Detoxication Mechanisms, 2nd ed., pp. 293-295. Chapman and Hall, London.

Received for publication March 9, 1971. 